\title{
Proposal for the development of a national open access database in Vietnam and comparison with other Asian countries' national literature databases
}

Received: September 16, 2019 Accepted: November 1, 2019

Correspondence to Tien-Trung Nguyen nttrung@moet.gov.vn

ORCID

Loc My Thi Nguyen

https://orcid.org/0000-0002-7810-5262

Tien-Trung Nguyen

https://orcid.org/0000-0002-3320-8962

Thanh Thi Nghiem

https://orcid.org/0000-0002-4516-9630

Hien Thu Thi Le

https://orcid.org/0000-0001-8847-6369

Thao Phuong Thi Trinh

https://orcid.org/0000-0001-6277-4907

Thuan Van Pham

https://orcid.org/0000-0003-0805-5084

Thanh Chi Nguyen

https://orcid.org/0000-0001-8533-2925

Linh Khanh Hoang

https://orcid.org/0000-0003-0131-7838

Trung Tran

https://orcid.org/0000-0002-0459-7284
Loc My Thi Nguyen', Tien-Trung Nguyen ${ }^{2,3}$, Thanh Thi Nghiem', Hien Thu Thi Le', Thao Phuong Thi Trinh", Thuan Van Pham', Thanh Chi Nguyen', Linh Khanh Hoang², Trung Tran ${ }^{5}$

${ }^{1}$ VNU University of Education, Vietnam National University, Hanoi; ${ }^{2}$ Institute of Theoretical and Applied Research (ITAR), Duy Tan University, Hanoi; ${ }^{3}$ Vietnam Journal of Education, Hanoi; ${ }^{4}$ Thai Nguyen University of Education, Thai Nguyen University,

Thai Nguyen; ${ }^{5}$ Vietnam Academy for Ethnic Minorities, Hanoi, Vietnam

Abstract

In the context of the need to ensure appropriate signalling of the publication of high-quality, international-calibre publications in Vietnam, as well as new policies to improve the quality and effectiveness of scientific research in Vietnam, it is practical to investigate the possibility of developing a national open access database (NOAD). This study aims to answer the question of whether it is necessary to establish a NOAD in Vietnam. We used document analysis to evaluate issues related to NOADs. The results of this study show the complexity, lack of consistency, and difficulty in obtaining practical statistics and assessing research and scientific records in Vietnam today. Furthermore, the findings of this study imply that it is necessary to establish a NOAD of scientific research in Vietnam. The information in this report can be used to develop a NOAD for Vietnam in particular, and for any country that lacks one in general.

Keywords

Open access; National database; Vietnam

\section{Introduction}

Background: The question of open or closed access to scientific publications is still a subject of debate. Nonetheless, open access (OA) has become a growing trend; worldwide, in 2011, 11\% of all journal articles were published in fully OA journals [1,2]. Scopus 2018 report stated that over $16 \%(3,600$ of 21,950) of Scopus-indexed journals were fully OA [3]. This trend toward more

This is an open access article distributed under the terms of the Creative Commons Attribution License (https://creativecommons.org/licenses/by/4.0/) which permits unrestricted use, distribution, and reproduction in any medium, provided the original work is properly cited. 
widespread OA represents significant progress towards the academic goal of improving fundamental knowledge, and it is the next step in transforming the online versions of journals [4]. The concept of OA also appears to align with the secondary goal of enhancing the influence of scientists and journals.

Vietnam lacks a national database system to archive, systemize and comprehensively evaluate science and technology research. Even without a national database available, it is possible to use several online databases, such as the National Open Database of the Ministry of Science and Technology [5], the National Library of Vietnam [6], and the Vietnam Citation Gateway (V-CitationGate; created at Vietnam National University, Hanoi) [7], although these are quite limited. Furthermore, efforts to develop a national scientific database have been fraught with inconsistent information and inefficiencies stemming from the existence of multiple other projects at the same time.

Purpose: The aim of this study is to propose the development of a national OA scientific database in Vietnam based on relevant research on this issue in other Asian-Pacific countries. Specifically, we reviewed the Directory of Open Access Journals (DOAJ) [8], Google Scholar [9], the national citation index system and the national OA database of scientific research in selected countries. Then, we reviewed the current status of Vietnam's national OA database of scientific research. Finally, we proposed appropriate policy recommendations.

\section{Methods}

This research was largely based on the use of document analysis to evaluate issues related to OA databases. The selected materials were OA-related articles with keywords such as "OA," "DOAJ," "Google Scholar," "science editing," or "national database"; Vietnamese policy documents related to the evaluation of scientific journals, either OA or closed access (from Vietnam's Ministry of Science and Technology and Ministry of Education and Training [MoET]); and information about policies related to the academic evaluation systems of some countries in the region. All OA-related information presented in this study is based on published descriptions or the official websites of the systems under analysis.

\section{Results}

\section{$\mathrm{OA}$ in some Asian countries}

The European Union [10] stated that "OA" refers to the free access of knowledge to all users, as well as the ability for authors and copyright holders to reserve the rights to allow all users to access, copy, recite, distribute, broadcast and display the research findings free of charge; to create and distribute derivative products in any digital means for any responsible purposes in accordance with copyright laws; and to create a limited number of copies for their personal use. This can be considered a broad definition of $\mathrm{OA}$ in research and publication.

According to the DOAJ, the 10 Asian countries ranking highest in the number of full-text OA journals are in Table 1 [8]. These results show the level of openness and participation of these countries in the DOAJ. Leading the list is Indonesia, and at the bottom of the list is Japan. To make appropriate recommendations for Vietnam, we examined the policies on OA databases or archive systems of several Asian-Pacific countries, including Indonesia, Thailand, Singapore, Malaysia, Laos, Cambodia, Myanmar, Brunei, Korea, Japan, and Australia.

Indonesia has the second-largest number of OA journals in the world. Despite the nation's policies that encourage OA publication, it was not until 2018 that Indonesia set up the Indonesian Publication Index [11], initiated by the Indonesian Institute of Advanced Engineering and Sciences and later managed by Indonesia's Ministry of Research and University Education. The Indonesian Publication Index was designed to approve, index, evaluate, supervise and improve the quality of academic publications in Indonesia.

Thailand unofficially introduced the Thai-Journal Citation Index (TCI) in 2001 (and officially established it in 2004) to evaluate the impact indicators of Thai journals following a proposal by Professor Narongrit Sombatsompop [12]. The main goals of the TCI are to motivate an improvement in the quality of Thai journals and to disseminate research findings for the benefit of the society and the community. The official website of the TCI is written in Thai, which clearly shows that its intended audience is Thai speakers. TCI-indexed journal articles are weighted 0.75 , in comparison to a weight of 1.0 for Thomson-indexed international journal articles.

Singapore has not developed its own citation index. However, a Singaporean working team for the ASEAN Citation

Table 1. Top 10 countries in Asia, with regard to the number of full-text open access journals in the DOAJ, 2019 [8]

\begin{tabular}{|c|c|c|c|c|c|c|c|c|c|c|}
\hline & Indonesia & Iran & India & $\begin{array}{c}\text { China } \\
\text { (China and } \\
\text { Taiwan) }\end{array}$ & Korea & Malaysia & Pakistan & Iraq & Japan & Thailand \\
\hline No. of journals & 1,554 & 509 & 281 & 136 & 115 & 69 & 56 & 41 & 33 & 29 \\
\hline
\end{tabular}


Index (ACI) was established in 2014 and led by Professor Michael Khor, with the aim of helping Singapore-based journals to join the ACI. The objectives of the working team are as follows: regarding journals which are not yet listed in Web of Science (WoS) and Scopus, to approach, support and sponsor them to join WoS and Scopus; regarding WoS and Scopus-indexed journals, to list them in the ACI. Hopefully, this will increase the chance that these journals are cited and give their researchers access to high-quality research findings.

Malaysia's Ministry of Education established the Malaysian Citation Centre (MCC) in 2013 [13]. The MCC is responsible for contrasting, monitoring, coordinating and improving the quality of academic journals in Malaysia. The MCC maintains a citation index called the Malaysian Citation Index, or MyCite. MyCite provides access to indexes as well as full-text articles from scholarly journals published in Malaysia in the fields of science and technology, medical science, and social and human sciences. Additionally, MyCite offers citation reports and indexes of Malaysian authors, journals and organisations based only on the content of MyCite.

No plans have been announced for the development of the Laos Citation Index, the Cambodia Citation Index, the Myanmar Citation Index, or the Brunei Citation Index. However, the ACI has been active in these countries, with activities including organising conferences, assisting local journals in accessing the ACI's information and creating standards that must be met to join the ACI.

In South Korea, the government officially encourages the development of full-text OA journals. In particular, it is legally mandated that the full text of government-sponsored social science or humanities research be published in an OA database, either in the South Korean citation index created by the government or in the WoS and Scopus indexes. The Korea Citation Index is a citation database of more than 2,000 Korean academic journals, covering all fields of science and technology, medicine, social and human sciences; this is similar to WoS and Scopus. Journal Article Tag Suite (JATS) 1.0 is an application that is widely used in South Korea to publish Korean-language journal articles in XML. This is relevant to Vietnam with regard to the development of an OA database in Vietnamese, the national language.

In accordance with international standards, Japan developed its own database, the Japan Science and Technology Information Aggregator, Electronic (J-STAGE). This platform is managed by the Japan Science and Technology Agency and has an interface in both Japanese and English [14]. Its objectives are to enhance the dissemination of information and to internationalise academic findings related to science and technology in Japan. This objective is highly relevant to Vietnam, as the dissemination of information and the internationalisation of academic findings related to science and technology would help scientists in Vietnam and beyond to assess the quality of their research papers and would improve the accessibility and ease of international citations.

The Australian Research Council (ARC) was established in 2001, with the mission of advising the Australian government in researching, monitoring, managing and sponsoring grants for the National Competitive Grants Program. It plays an essential role in investment in Australian research and development and is responsible for evaluating and selecting research

Table 2. Status of national open access database of scientific research in several Asian-Pacific countries

\begin{tabular}{lccc}
\hline Country & $\begin{array}{l}\text { National open } \\
\text { access database }\end{array}$ & & \\
\hline Thailand & Yes & Yes https://www.tci-thaijo.org/ & Government-sponsored \\
Indonesia & Yes & Yes http://id.portalgaruda.org/ \\
Malaysia & Yes & Yes http://mycc.my/ \\
Myanmar & No & No & - \\
Laos & No & No & - \\
Cambodia & No & No & - \\
Philippines & No & No & - \\
Singapore & No & No & - \\
Vietnam & No & No & - \\
Japan & Yes & Yes https://www.jstage.jst.go.jp/ \\
Australia & Yes & Yes https://www.alia.org.au/about-alia/policies-standards-and-guidelines/alia-open-access-statement \\
South Korea & Yes & Yes https://www.kci.go.kr/kciportal/main.kci \\
& & & http://www.nrf.re.kr/eng/index \\
\hline
\end{tabular}


for the Excellence in Research for Australia program. The ARC's goals are to improve knowledge and innovate for the benefit of the Australian community through sponsoring the highest-quality research; to evaluate the quality and influence of the research; and to advise on research problems. The ARC is Australia's leading consulting body on the national initiative to invest in research. The ARC also sponsors various organisations, individuals and areas of research for the benefit of the national economy, culture, community and environment. In 2017, the ARC established the ARC Open Access Policy (version 2017.1), which includes a key condition that research output must be made openly accessible [15]. The Australian Library and Information Association promotes the free flow of information and ideas through OA to recorded knowledge, information and creative works. The above analysis can be summarized in Table 2.

\section{Vietnam scientific database system}

In Vietnam, no national database serves as the official reference for the two most prestigious national Scientific Evaluation Committees in the field of science and technology, namely the State Council for Professorship (SCP) [16] and the National Foundation for Science and Technology Development (NAFOSTED) [1,17].

The SCP is a prestigious committee composed of leading scientists from all fields and interdisciplinary specialties; these experts have the responsibility of considering and approving eligible candidates for professorships every year. They also advise the MoET on guidelines to further develop the cadre of professors, to improve the quality of doctoral training and to develop policies to grow the professoriate [16]. The publication-related criteria (journal articles and books used at the university level and above) of the SCP refer only to WoS and Scopus, and they mention the impact factor as well as the ranking (from Q1 to Q4) of a journal article without referring to the DOAJ or GS. More specifically, in the area of education (which includes four disciplines: General Education, Didactics of School Subjects, Educational Management, and Education of Specific Branches), the criteria used by the SCP for assessing the international journal articles published by candi- dates include (for WoS-indexed journals) the impact factor according to the Science Citation Index, the Science Citation Index Expanded, the Social Sciences Citation Index, and the Arts and Humanities Citation Index and (for Scopus-indexed journals) the ranking of the journal. The SCP of education additionally considers the reputation of other international journals in the field. No official criteria exist to evaluate the reputation of journals that do not belong to the abovementioned indexes. The specific criteria are decided depending on the area and on experts' evaluation of the specific articles and journals. The same situation applies to 27 other fields.

NAFOSTED has promoted research in Vietnam since its establishment in $2008[1,18]$. In order to register for research projects with NAFOSTED, authors are required to have WoS or Scopus-indexed publications. Moreover, NAFOSTED provides an annual list of prestigious journals and publishing houses as a guide for scientists. Accordingly, in addition to the core lists of WoS and Scopus, each disciplinary committee proposes a list for their own field (for example, the list for social and human sciences, issued annually since 2017). This list consists of reputed Vietnamese journals that scientists are encouraged (but not mandated) to publish in in order to receive NAFOSTED research grants.

The documents published by SCP and NAFOSTED clearly demonstrate the differences between the two evaluation systems (Table 3). Furthermore, it can be difficult to look up information about the domestic publications of candidate journals, which must be done manually, as there is no online database.

In 2016, the V-CitationGate was established at Hanoi National University of Education as a bibliographic database and a centre for the analysis of science, technology and innovations in Vietnam. Developed by the Vietnam National University, Hanoi, V-CitationGate consists of information (summary and/or full-text) regarding contemporary publications (journal articles and books), inventions, and in particular the rare and ancient materials that are collected, digitalised and integrated from various archive sources in Vietnam and overseas [7]. According to V-CitationGate, there are currently 66 $\mathrm{OA}$ academic journals, including 9 Vietnamese-owned journals that are internationally published.

Table 3. Lists of prestigious journals and publishing houses recommended by SCP and NAFOSTED

\begin{tabular}{llll}
\hline Committee & Scientific field & Prestigious international journals and publishing houses & Prestigious national journals \\
\hline SCP & All & $\begin{array}{c}\text { Annually revised list (WoS, Scopus, and an additional list } \\
\text { of prestigious journals and publishing houses) }\end{array}$ & List of field-based journals with scores (SCP list 1) \\
NAFOSTED & Natural sciences & Annually revised list (WoS, Scopus, etc.) & Annually revised list \\
& Social sciences & Annually revised list (WoS, Scopus, etc.) & Journals in SCP list 1 (maximum weight, 1) \\
\hline
\end{tabular}

SCP, State Council for Professorship; NAFOSTED, National Foundation for Science and Technology Development; WoS, Web of Science. 
Another system under development is the Vietnam Citation Index (VCI), the official website of which falls under the MoET [19]. The VCI is stated to be under development by the National Professor Committee. However, as the information about this organisation is still "in the pilot period," it is difficult to draw conclusions.

More recently, the research team of Quan-Hoang and Vuong proposed a database in the field of social sciences in Vietnam. The findings concerning the development and implementation of research based on the citations from this system have been noticeable in Vietnam.

Nonetheless, the abovementioned databases under development still lack adequate attention and investment. Moreover, no reference to these databases has been made in any documents of the two most prestigious scientific bodies in Vietnam, namely SCP and NAFOSTED.

\section{Discussion}

Based on the theoretical and empirical findings presented above, we propose the following recommendations for Vietnam. It is necessary to develop an official system of evaluation in the fields of science and technology, as was done in Australia, Japan, and South Korea. Currently, the evaluation systems in Vietnam belong to separate ministries (Ministry of Science and Technology and MoET), leading to an absence of impact on national science policies and a lack of consistency across different scientific fields and national-level research projects. The National Science and Technology Citation Index should be open-even fully open-access. We recommend developing the interface in both the national first language (Vietnamese) and English. This is advised based on research on countries that use English as a second or foreign language.

Developing a national database in Vietnam is highly feasible due (at least) to the three following reasons: first, most publications in Vietnam are written in Vietnamese and have considerable scientific significance; therefore, these publications need to be evaluated by Vietnamese specialists with the corresponding expertise. Secondly, the database would serve as a reference framework for scientists, journal editors and others in the field to gain a general picture of the national and international research situations. Thirdly, the categorization criteria used by the existing databases are inconsistent, raising the need for a set of criteria that are properly designated in the context of Vietnam and that satisfy international requirements.

It is essential to develop a Vietnamese OA database of science (VOADS). The first objective is to publish and disseminate academic research findings and scientific profiles of all authors. This system would provide an identification number for each Vietnamese scientist as a code for evaluation committees (such as SCP and NAFOSTED) to search, report and rapidly and automatically evaluate their scientific research competency. The system would also categorise and assess journals, publishing houses and state-owned authorities (institutes, universities, etc.). Accordingly, the government could introduce policies regarding the priority of investment in and the incentivization of science and technology research based on a precise digital database. The VCI would be part of this national database of science and technology. We recommend creating a timeline to develop VOADS in line with other international $\mathrm{OA}$ databases in terms of data structure and data information to facilitate integration and communication with worldwide databases.

Of course, certain disciplines of scientific research require special attention, such as politics, the military and national security.

Importantly, the foremost objectives of developing VOADS are to evaluate policies regarding science and technology development, to assess the fields of science and technology, and to help identify high-performing research teams and scientists. The task of developing academic journals only follows as a subsidiary mission, along with furthering science and technology in Vietnam.

A widespread trend for many countries in the Asia-Pacific region is to develop and publish research in their own national scientific databases. WoS and Scopus remain the most prestigious publication databases. Despite differences between databases in the levels of and requirements for openness, $\mathrm{OA}$ is an undeniably growing trend. The criteria and databases used for evaluation in each country also vary widely. This means the evaluation of the scientific quality of new databases is still in progress and takes a relatively long time. Both within a country and between countries, different approaches exist in employing and evaluating these databases. Nonetheless, there are two main objectives of the development of national databases: to evaluate, identify and invest in higher-value research teams and fields from the perspective of effective economic and social development; and to categorise and evaluate scientific fields, scientists, research organisations and journals.

It is important to create a detailed timeline for developing VOADS to ensure the following: first, all academic publications (journal articles, books, etc.) should be required to be OA. Second, the national database should be connected to other OA databases for further development and to satisfy international requirements. In the development of this national database, we recommend considering all of the current criteria used by international databases. Third, it is necessary to assist and encourage Vietnamese scientists to use and join $\mathrm{OA}$ databases, starting with VCI, Google Scholar and DOAJ, 


\section{science editing/}

based around the world in order to better approach the international community and to improve their reputation. Fourth, cooperating with accredited international publishing houses or journals may also help lead to the introduction of Vietnamese publication brands with international standards.

\section{Conflict of Interest}

No potential conflict of interest relevant to this article was reported.

\section{References}

1. Seo TS. Open access full-text databases in Asian countries. Sci Ed 2018;5:26-31. https://doi.org/10.6087/kcse.114

2. Van Noorden R. Open access: the true cost of science publishing. Nature 2013;495:426-9. https://doi.org/10.1038/495426a

3. Elsevier. Scopus content coverage guide [Internet]. Amsterdam: Elsevier; 2017 [cited 2019 Oct 30]. Available from: https://www.elsevier.com/?a=69451

4. David PA. Common agency contracting and the emergence of 'open science' institutions. Am Econ Rev 1998;88:15-21.

5. National Agency for Science and Technology Information [Internet]. Hanoi: Ministry of Science and Technology; 2019 [cited 2019 Oct 30]. Available from: http://www.vista.gov.vn/Default.aspx?tabid=115\&IntroId=292\&temidcli cked $=292$ \&language $=$ vi $-\mathrm{VN}$ )

6. National Library of Vietnam (open resources) [Internet]. Hanoi: Ministry of Culture, Sports and Tourism; 2019 [cited 2019 Oct 30]. Available from: http://nlv.gov.vn/ef/

7. Vietnam Citation Gateway [Internet]. Hanoi: Vietnam National University; 2019 [cited 2019 Oct 30]. Available from: https://vcgate.vnu.edu.vn/

8. Directory of Open Access Journals [Internet]. [place unknown]: Directory of Open Access Journals; 2019 [cited 2019 Oct 30]. Available from: https://doaj.org/

9. Google Scholar [Internet]. Mountain View: Google; 2019 [cited 2019 Oct 30]. Available from: https://scholar.google. com.vn/

10. European Union. Open access: opportunities and challenges. Brussels: European Union; 2008.

11. Indonesian Publication Index [Internet]. [place unknown]: Institute of Advanced Engineering and Science; 2019 [cited 2019 Oct 30]. Available from: http://id.portalgaruda.org/

12. Thai-Journal Citation Index Centre [Internet]. Bangkok: Thai-Journal Citation Index Centre; 2019 [cited 2019 Oct 30]. Available from: https://www.kmutt.ac.th/jif/public_ $\mathrm{html} /$

13. Malaysia Citation Centre [Internet]. Putrajaya: Pusat Sitasi Malaysia; 2019 [cited 2019 Oct 30]. Available from: http:// mycc.my/

14. Japan Science and Technology Agency [Internet]. Tokyo: Japan Science and Technology Agency; 2019 [cited 2019 Oct 30]. Available from: https://www.jstage.jst.go.jp/browse/char/en

15. Australian Research Council. ARC Open Access Policy Version 2017.1 [Internet]. Canberra: Australian Research Council; 2019 [cited 2019 Oct 30]. Available from: https:// www.arc.gov.au/policies-strategies/policy/arc-open-accesspolicy-version-20171

16. The State Council for Professorship [Internet]. Hanoi: Ministry of Education and Training; 2019 [cited 2019 Oct 30]. Available from: http://hdgsnn.gov.vn/

17. National Foundation for Science and Technology Development [Internet]. Hanoi: Ministry of Sciences and Technology; 2019 [cited 2019 Oct 30]. Available from: https:// nafosted.gov.vn/en

18. Vuong QH. Open data, open review and open dialogue in making social sciences plausible. 2017 Dec 12 [Internet]. Nature Scientific Data Updates; 2017 [cited 2019 Oct 30]. Available from: https://ssrn.com/abstract=3086667

19. Vietnam Citation Index [Internet]. Hanoi: State Council for Professorship; 2009 [cited 2019 Oct 30]. Available from: https://www.vci.gov.vn/ 